\title{
Aplicação Administrativa do Direito
}

\author{
(Sintese de Hermenêutica)
}

Celso de Magalhães

I - INTRODUÇ̃̃o

N Ão são apenas ós magistrados que devem saber o alcance das leis e dos textos normativos. Muita questão de direito se discute e se resolve à revelia dos Tribunais, nos vários departamentos da Arministração Pública, civil ou militar. Pode-se mesmo dizer que a Justiça é reclamada com mais insistência junto aos administradores, que junto aos juízes. É que, para chegar até êstes são necessários conhecimentos e dinheiro, o que, como regra, não se exige nas questões administrativas.

Decidindo do direito alheio, o administrador honesto, civil ou militar, assume grande responsabilidade, pois está sempre entre as pontas do dilema: o prejuízo da parte, ou o prejuízo do erário. Não optar, preliminarmente, nem por um, nem por outro, descobrir a verdadeira razão, o sentido exato do texto a aplicar, eis o seu dever. Todavia, para cumpri-lo, quantas labutas, quantas canseiras!... E quando a consciência levanta uma dúvida sôbre a decisão final, quanta preocupação!...

A solução de um caso concreto que se apresente ao administrador, depende da maneira pela qual será por êle interpretada a regra de direito reguladora da espécie. E como a interpretação é a cúpola de todo o edifício jurídico sem ela de nada valem códigos; leis, regulamentos...

De uma interpretação correta é que depende o reconhecimento da validade ou não de direitos, por vêzes de alta relevância.

Quando se trata de um simples artigo de jornal, várias pessoas que o lêem podem interpretá-lo diferentemente. Não obstante, um artigo é ridigido de modo a que o assunto fique, não raro, exaustivamente esplanado, parecendo, ao autor, não deixar margem a que the duvidem do pensamento. Ora, num texto normativo, sintético por natureza, a divergência de opiniões é muito mais freqüente.

Daí a necessidade de uma ciência - a Hermenêutica, que se destina a formular princípios e estabelecer regras para a exata compreenção dos textos.

Quem não conhece essas regras, não pode ser bom aplicador do Direito; participando dos negócios públicos, terá - se fôr honesto - de andar jus- 
tamente preocupado pela ameaça constante que êle mesmo se constitui para o reconhecimento da verdadeira justiça.

Nas repartições públicas, civis e militares, há muita gente nesse caso.

Para essa gente foi feita a presente síntese, que nada mais é senão um resumo daquilo que os Mestres ensinam e espalhado se encontra em vários livros.

E uma síntese para auxílio daqueles que não puderam, ainda, fazer do assunto, estudo mais profundo. Nela se veja apenas o propósito de divulgar e jamais o desejo estulto de dar regras a mestres e sabedores.

\section{II - A CIÊNCIA DA INTERPRETAÇÃO}

Hermenêutica - A arte de interpretar os textos, isto é, a arte de compreender os códigos, as leis, os regulamentos, tôdas as normas, enfim, chamase - Hermenêutica.

Interpretar é explicar, mostrar o verdadeiro sentido da expressão; é, pois, extrair do texto, tudo quanto êle pode conter. As leis, obra humana que são, padecem das próprias imperfeições dos homens; cumpre, então, verificar, com esmêro, qual o "alcance", qual o sentido das prescrições que nela se contêm, qual o significado exato daquilo que pretenderam regular.

Análise - Por uma cuidadosa análise do texto é que poderá o intérprete chegar a compreensão exata das regras estabelecidas. Mas essa interpretação não deverá ser feita in abstrato. O caso concreto que se apresenta a exame deve ser cuidadosamente considerado. E, para estabelecer a relação entre êle e o texto que, possivelmente, o regula, cumpre descobrir o "alcance" da regra normativa, o que ela, realmente, quer dizer, a que ponto visou chegar.

Interpretação - Para conseguir êsse resultado, estudam-se os vocábulos, procura-se o sentido das expressões, a relação recíproca das orações no período, compara-se o trecho estudado com outros trechos semelhantes da mesma lei ou com leis parecidas, nacionais e estrangeiras; indaga-se qual seria a finalidade que se teve em vista conseguir com a inclusão da regra considerada naquele texto, isto é, qual o objetivo da lei, qual sua posição em face das normas gerais de Direito; estudam-se os documentos relacionados com a elaboração da regra a interpretar, tudo num trabalho exaustivo, para que a verdade resulte clara e a justiça se faça.

Alcance - A lei, ainda que elaborada com o máximo escrúpulo, e por pessoas de notória capacidade, não poderia prever todos os casos possíveis; ela traça normas gerais, de larga amplitude, embora claras e precisas como o sóem ser. Ademais, deve adaptar-se à evolução da vida, aos fenômenos imprevistos, que vão surgindo diáriamente, e aos quais o legislador não poderia ter atendido, pois inexistiam à época da elaboração do texto.

E ao intérprete que compete sanar essas lacunas inevitáveis dos textos normativos; modernizar as normas, substituir até, por vezes, o próprio legislador, como se a lei houvera de ser feita naquele mesmo momento de sua aplicação, considerando o caso novo surgido. 
Aparência - O aspecto visível da norma, constitui apenas uma parte da composição do texto; a outra parte está no sentido íntimo da regra legislada. Descobrir êsse sentido íntimo é a finalidade da Hermenêutica, a razão de ser da arte de interpretar os textos normativos.

Requisitos - As garantias de uma boa interpretação, repousam nas próprias qualidades do intérprete: honestidade de propósitos, inteligência e cultura. Quanto mais completas forem essas quantidades, mais perfeitas e seguras serão as conclusões intepretativas. Mais perfeita, consequientemente, a aplicação do Direito, a distribuição da Justiça.

Da cultura necessária ao bom intérprete, faz parte o estudo da Hermenêutica. Estudar as regras e princípios que ela estabelece é demonstrar respeito e consideração ao direito alheio e oferecer sólida garantia na defesa do patrimônio público.

\section{III — FORMAS DE INTERPRETAÇÃO}

Espécies - Há várias formas de interpretar um texto normativo:

- autêntica

- doutrinária

- legislada

Autêntica - A interpretação se diz autêntica, quando feita pelo próprio órgão e através às mesmas pessoas que elaboraram a norma. E óbvio que, em qualquer época, se pode fazer uma interpretação autêntica, ainda que muito tempo já se haja decorrido desde quando elaboraram o texto. Mas, se essa interpretação se verifica depois que o referido texto já foi, por muitas vêzes, aplicado, será sempre causa de tumulto na vida jurídica ou administrativa do país. Se respeitada, como válida, certa regra, durante muito tempo, verifica-se, afinal, que seu sentido deve ser modificado, os transtornos são inevitáveis.

Retroatividade - No caso da interpretação autêntica, não há retroatividade; daí persistirem, em tôda a plenitude, os julgados já feitos, as decisões já proferidas, tudo conforme a compreensão primitiva do texto alterado. E justamente isso que gera o tumulto: variedade de decisões com apoio no mesmo texto normativo. Melhor será que, em se reconhecendo defeito no texto, se proceda à sua derrogação ou revogação definitiva, antes que recorrer a uma interpretação autêntica, para ajustá-lo às necessidades gerais .

Doutrinária - E a interpretação que obedece a princípios e regras. Tanto a que se faz nos Tribunais e Juízos - e que por isso se chama judiciária - como a que se faz nas esferas administrativas, pelos diversos aplicadores do Direito, é interpretação doutrinária. Essa é a única que realmente merece o nome de interpretação.

Sómente ela representa um ato livre da inteligência humana; sómente ela não obedece a injunções estranhas, como sói acontecer com a interpre- 
tação autêntica. Os Tribunais a fazem por manifestação independente, ou a fazem os pesquisadores, os eruditos, em busca, simplesmente, da verdade científica.

Legislada - Há códigos que incluem, no seu contexto, regras de interpretação. Muitos doutores opinam contràriamente à essa prática. Se a verdadeira interpretação é a doutrinária, não parece bem sujeitar uma interpretação a preceitos rígidos, como serão, sem dúvida, aquêles incluidos num código ou numa lei qualquer. É que faltaria, no caso, a elasticidade com que se evitam os inconvenientes da aplicação da norma às realidades concretas.

Interpretação Interpretada - Por outro lado, as regras incluídas no texto legal obrigam tanto, quanto os demais preceitos também nêle contidos, e são, como êles variáveis no decorrer dos tempos. Assim sendo, é claro que tais regras carecem também de interpretação; elas não são absolutas, pois se o fôssem, constituiriam exceção aos demais dispositivos do mesmo texto, todos elásticos, flexíveis, adaptáveis às necessidades. Chegar-se-ia, portanto, à conclusão de reconhecer que as regras de interpretação contidas na lei, também careceriam de interpretação. E estaria furmado o círculo vicioso.

Obrigatoriedade - Ademais, constitui matéria controvertida saber até que ponto obrigam as regras de interpretação contidas num texto legal qualquer, isto é, não se sabe ainda se elas obrigam apenas quanto aos dispositivos do mesmo código ou norma, ou se, pelo contrário, obrigam de modo geral, prevalecendo, também, na interpretação de textos e normas diferentes. Assim, por exemplo, em relação às regras contidas no Código Civil, não existe ainda unanimidade no entender que elas devem obrigar sòmente em assuntos de Direito Civil, ou se também prevalecem no Direito Penal, no Direito Trabalhista etc.. Havendo ilustres Mestres, num e noutro sentido, claro que de qualquer dos lados estará o administrador em boa companhia. Não obstante, parece conveniente atender às regras legais, apenas quando se tratar de interpretação de preceitos contidos no próprio corpo normativo, onde tais regras se encontrem; fora daí, resultará melhor o prevalecimento das regras gerais da ciência que, é óbvio, em muitos pontos hão de se assemelhar às contidas em qualquer código, seja qual fôr sua especificidade.

\section{IV - ERROS}

Requisitos - Não resta a menor dúvida: interpretação é obra de lógica, de bom senso, de raciocínio. Isso não significa, porém, que seria bastante aplicar, no exame de um trecho normativo, os princípios da ciência do pensamento certo, para conseguir apreender-lhe o significado exato. Tôda interpretação fica na depedência da sabedoria, da cultura, da ilustração e preparo do intérprete, além de exigir dêle uma boa dose de experiência.

Não poderá haver bom intérprete sem probidade, critério, senso de medida. As regras gerais da Hermenêtica, por si sós, não bastam à exegese das leis, porquanto tôda obra de lógica, como é a interpretação, depende, em grande parte, das características de quem a realiza, isto é, da equação pessoal do aplicador da norma. 
Evidentemente, se faltar ao intérprete qualquer de tais requisitos, o alcance que êle atribuir ao texto do qual fêz a exegese será errado; errada será sua interpretação.

Arestos - O texto de uma norma nada mais é que a matéria prima a ser plasmada pelo aplicador do Direito; conseqüentemente, em tôda interpretação haverá um cunho especial, uma característica pessoal do exegeta. E descabido, portanto, aplicar o Direito, tomando por base apenas arestos e julgados, isto é, a maneira pela qual já foi anteriormente decidida uma questão. Cada caso submetido ao exame do intérprete, tem suas peculiaridades. Não há, entre duas questões jurídicas, identidade absoluta; qualquer diferença entre elas pode conduzir a uma interpretação também diferente. Arrisca-se, pois, a cometer erros, o exegeta que aplica, indistintamente, decisões anteriores a casos supervenientes.

Jurisprudência - Os julgados, a jurisprudência, servirão tão-sòmente como auxiliar da interpretação. Se um caso tal foi resolvido de certa forma, isso não significa que todos os outros casos, embora se apresentem semelhantes, devam ser resolvidos do mesmo modo. Se assim fôsse, o Direito não evoluiria e, de imediato, prejudicada uma das grandes necessidades sociais. É preciso considerar que, debaixo de aparências semelhantes, dois casos podem diferir, grandemente, pelo seu aspecto jurídico. O aplicador do Direito está, pois, na obrigação de fazer um estudo conciencioso de cada caso em particular, e não se deixar influir pelos julgados anteriores, isto é, pelas decisões que, na espécie, já proferiram juizes ou órgãos administrativos. Assim, o demasiado apêgo à jurisprudência pode conduzir a erros graves.

Letra e Espírito - A letra da norma escrita não representa tudo dentro dela; é justamente por isso que se busca interpretá-la. O exegeta procura descobrir, no trecho submetido a seu exame, o respectivo alcance, o conteúdo, o espírito; mas, em o fazendo, deve cuidar para que force o sentido, não amplie ou restrinja demais, atingindo assim a situações evidentemente fora dos limites compreendidos na norma considerada.

Preconceito - Nenhuma interpretação poderá ser levada a bom têrmo, quando, ao iniciar seus trabalhos, possui o exegeta uma idéia preconcebida, quando já formulou um prejulgamento. É necessário que o exame da norma discutida se faça sem parti-pris, com isenção de ânimo, desprovido o intérprete de paixões. Inegávelmente, tôda inclinação simpática ou antipática oblitera o raciocínio necessário à boa interpretação, conduzindo o aplicador do Direito a erros que poderiam ser evitados.

Idéias Dominantes - Todo intérprete vive num meio onde, não raro, predominam certas idéias, por vêzes relacionadas com o assunto submetido à sua análise. Ora, essas idéias dominantes no lugar, onde o exegeta vive ou age, podem levá-lo a uma interpretação errada. Justamente por serem idéias dominantes é que existem o perigo de serem aceitas sem exame. Dessa forma é que resultam absurdas muitas de nossas atitudes. Quem deseja interpretar com acêrto e honestidade deve abster-se de tomar conhecimentos de tais idéias das opiniões generalizadas, pelo menos na fase preliminar de seus trabalhos. Depois que, à luz da ciência, chegar o intérprete a uma conclusão, 
embora precária, não é demais, é mesmo conveniente que tome contato com as idéias predominantes, para um reajustamento final. Antes disso, não, que pode prejudicá-1o.

Conduta - O intérprete deve estar sempre desconfiado consigo mesmo e, por isso cumpre-1he sopesar bem os prós e os contras da questão em estudo, antes de manifestar-se sôbre ela. Não se lhe deve afastar do espírito a possibilidade de êrro, o desvio do assunto por motivos inapreciáveis, para que não conclua apressadamente, não decida antes de verificar o acêrto das conclusões, pelas contraprovas possíveis.

Para evitar as paixões, é preciso educar bem a vontade, zelar pela saúde e adquirir, tanto quanto possível, o domínio próprio. Um bom intérprete terá de ser frio insensível, ante o caso concreto, como frio e insensível é o matemático ante as equações a resolver.

Com tais cuidados, sem paixões profundas e com uma base cultural respeitável, diminuem ou mesmo desaparecem as possibilidades de êrro na interpretação. Mas, para conseguir cultura, para adquirir o preparo intelectual indispensável, não bastam os estudos comuns, a aquisições dos conhecimentos rotineiros, especializados. E necessário muito mais. O intérprete deve ler de tudo - Filosofia, Literatura, Ciência, arrozoados de processos sentenças etc...., que tudo isso the poderá servir um dia na compreensão dum texto, no estudo duma norma a aplicar.

E possuidor de tais qualidades, não constituirá o aplicađor do Direito um fator de lesão ao patrimônio alheio, veículo de injustiças e descontentamento social.

\section{$\mathrm{V}$ - SISTEMAS}

Exeǵese - A interpretação dos textos chama-se - exegese. Ora, a primeira idéia que ocorre a quem, lendo um trecho escrito, não atinar com seu verdadeiro sentido é indagar de quem o redigiu, qual seu verdadeiro pensamento. Se a base da norma escrita é a lei, torna-se evidente que, mais apropriado seria caber ao órgão que elaborou, a respectiva exegese.

Interpretaçãc: Autêntica - É, como já foi dito, o que se chama de interpretação autêntica.

Todavia, não é fácil, como parece, a interpretação autêntica. Via de regra, as leis provêm de câmaras legislativas; a essas câmaras se pediria a interpretação do texto duvidoso. Ora, para que de fato, se tivesse uma interpretação autêntica, necessário seria que participassem do novo pronunciamento, os mesmos legisladores que participaram do primeiro. Isso é raro. Há mesmo casos em que isso se torna impossível: uma interpretação autêntica da Constituição, por exemplo, quando não mais existe a Assembléia Constituinte que a elaborou.

Ademais, quando a Câmara Legislativa interpreta um texto de lei anterior, terá de fazê-lo mediante nova lei que, nesse caso, revoga ou derroga a primeira. Não se trata, pois de uma verdadeira interpretação, mas de um novo diploma para regular o assunto. 
Por isso, a interpretação autêntica só tem valor teórico, carecendo de utilidade prática.

Interpretação Doutrinária - Para substitui-la surgiu a interpretação doutrinária. Essa é a que fazem Tribunais e Juízes, é a que fazem, também, os diversos aplicadores do Direito, nos vários setôres administrativos, e da qual existem diferentes modalidades.

Elaboração da Lei - A lei é na maioria das vêzes, elaborada por órgãos coletivos, por assembléias políticas, onde cada legislador discute as questões de um ponto de vista particular, visando, não raro, ao interêsse político, econômico ou religioso, e não, como seria de presumir, ao interesse imediato da matéria a regular. A lei não resulta, pois de uma vontade individual; ela é conseqüência do ambiente, surge como produto de vontades dominantes, trabalhadas, quase sempre, por fôrças subterrâneas, por fôrças que atuam no Inconciente, onde as fizeram nascer a hereditariedade, o elemento histórico, as tradições, as contigências da época.

Vontade do Legislador - Entre os vários legisladores que aprovam o mesmo texto, a maioria dificilmente o teria feito pelas mesmas razões: êste o faz por convicção científica, aquêle, por motivo filosófico, aqueloutro, para servir a seus eleitores, êste, ainda, por espírito de oposição... Ora, antigamente resumia-se a exegese na procura de uma presumida vontade do legislador. Mas onde encontrar no texto elaborado essa vontade, se ela se apresenta multiforme e, quiçá, indefinível?

Sistema Dogmático - Interpretar um texto, procurando descobrir qual a vontade do legislador que o redigiu, constitui o sistema dogmático, escolástico, tradicional ou psicológico. Se não havia a vontade de um, alegavam, havia, por certo, a vontade da maioria, o consenso do maior número. Ora, a verdade é que, numa câmara legislativa, é sempre a minoria - dada ao têrmo a significação quantitativa e não política - é sempre o menor número que discute e delibera, com a aprovação, muitas vêzes, inconsciente, mecânica, automática, displicente, do maior número. Mas, ainda êsse pequeno número não se manifesta homogêneo, pois representa tendências de diferentes matizes, apenas concordes na decisão final. Contudo, mesmo que essa vontade do legislador existisse, de que valeria ao aplicador do Direito conhecê-la, em época, por vêzes, muito distante do momento da elaboração do texto?

Sob a rigidez da forma, vai o Direito evoluindo e, conseqüentemente, não seria admissível que, ao fazer a lei, tivesse o legislador, como verdadeiro profeta, descoberto e precisado todas as situações futuras.

Assim, o sistema dogmático de interpretação dos textos não oferece interêsse; por seus defeitos e insegurança dos resultados, caíu em desuso, possuindo, atualmente, apenas valor histórico.

Sistema Evolutivo - A êsse sistema também se chama - históricoevolutivo, ou, simplesmente, evolutivo. A base em que êle repousa é a pro cura de uma adaptação do texto normativo às necessidades atuais, às mudanças de ambiente e de concepção, às épocas que se vão sucedendo, após o tex- 
to elaborado. Seu fundamento reside em que a lei deve ser interpretada conforme as circunstâncias existentes na data de sua aplicação. Os dogmáticos procuram conciliar o novo sistema com o tradicional que defendiam e, então, passaram a preconizar, não a procura da vontade do legislador, na época da elaboração do texto, mas de qual seria essa vontade, no momento atual, se fôsse o mesmo legislador chamado a regular o assunto, considerando os fatos concretos supervenientes.

Tanto o sistema dogmático, como o evolutivo, interessam pouco ao aplicador do Direito. É difícil e, quiçá, impossível, discenir seja o que o legislador quis, seja o que êle quereria, no momento de efetivar a fôrça legal do texto redigido.

Sistema Sociológíco - Não poucas vêzes, porém, a interpretação deixa de seguir qualquer de tais sistemas, passando a ser feita, com atenção apenas às necessidades sociais. Êsse sistema, chamado - sociológico, baseiase em que a lei deverá ser interpretada conforme os interêsses vitais da sociedade. O espírito do texto não é estático e, por isso, terá de sofrer variações, consoante variarem, também, as necessidades sociais.

Direito Livre - Acontece que, não raro, o sistema sociológíco pode adquirir demasiada amplitude, ultrapassando certos limites. Nesse caso, defendido por muitos, fica o aplicador do Direito com a faculdade de alterar os próprios têrmos da norma considerada, chegando até mesmo a regular o assunto, para suprir a inexistência de texto adequado. E' a isso que se denomina - direito livre, contra o qual se insurgem inúmeros tratadistas.

Inconvenientes - Ao administrador não é permitido adotar o sistema do direito livre, na interpretação dos textos a aplicar. Uma liberdade dessa seria, evidentemente, causa de tumulto, de anarquia na administração. Quando, entre os próprios juristas, grandes controvérsias ainda se suscitam por causa dessa tese revolucionária, perigosíssímo seria permitir ao administrador adotá-la no exercício de suas atribuições. Que os Tribunais o façam, ainda se tolera: maior é sua autoridade, por serem êles uma escola de juristas, todos presumìvelmente capazes de discenir, científicamente, até onde podem e devem chegar suas inovações, sem prejuízo da estrutura social. Suas decisões, por outro lado, sistematizam para o futuro, evitando o tumulto de decisões contraditórias. Nada ocorrendo, dessa espécie, com o administrador não se the permite a liberdade do - direito livre.

Processos ou Métodos - Para conhecer a verdadeiro sentido dum trecho escrito, o intérpréte pode valer-se de diferentes meios, aos quais se dá o nome de processos ou métodos. São vários êsses processos - filológico, lógicos, sistemático, histórico, teleológico. Nenhum dêles exclui os demais, isto é, nenhum dêles, por si só, seria capaz de conduzir, com absoluta certeza, ao conhecimento da verdade. O intérprete não deve usar de um só, mas, ao contrário, precisa contraprovar as conclusões obtidas por um dêsses processos, verificando a que resultado o conduzirá a aplicação doutro processo diferente. 